\title{
Patativa do Assaré: agente do sagrado
}

\author{
Patativa do Assaré: \\ agent of the sacred
}

Emerson Sbardelotti Tavares

\section{Resumo}

Antônio Gonçalves da Silva nasceu em 5 de março de 1909, em Assaré, no Ceará; foi um dos mais importantes representantes da cultura popular. Seu pseudônimo era Patativa do Assaré. Ganhou vários prêmios e títulos de Doutor Honoris Causa por suas obras. Faleceu no dia 8 de julho de 2002 em Assaré. Tem por objetivo verificar, apresentar e entender como sua poesia contribui e faz ligação para a Opção pelos Pobres pensada no Documento de Medellín a partir dos recortes de seus poemas sócio-religiosos. A pesquisa está alicerçada nas obras do Poeta, escritas por ele e sobre ele, e nas áreas do conhecimento pertinentes ao problema bem como da reflexão teológica necessária onde será possível a teorização sobre o tema. Sua vida e a obra apresentadas na relevância dos seus poemas, o significado religioso, social e político dos seus atos e a sua contribuição à cultura brasileira fazem com que o Poeta consiga, com singela beleza e arte, unir a denúncia social ao lirismo. $\mathrm{Na}$ sua poesia estão presentes as alegrias, as esperanças, as lutas do povo, ideias, palavras que se erguem com a dignidade dos que clamam por justiça, contra todas as formas de exploração do ser humano.

Palavras-chave: Patativa do Assaré. Opção pelos Pobres. 


\begin{abstract}
Antônio Gonçalves da Silva was born in march 5, 1909, in Assaré, in Ceará; was one of the most important representatives of popular culture. His pseudonym was Patativa do Assaré. Won several award s and titles of Doctor Honoris Causa for his works. Died on july 8, 2002 in Assaré. Aims to verify, present and understand how his poetry contributes and connects to the option for the poor thought Medellin document from the clippings of his poems religious partner. The research is based on the works of the Poet, written by him and about him, and in the areas of knowledge relevant to the problem as well as the theological reflection required where is it possible to be theorizing about the subject. His life and work presented at the relevance of his poems, the religious, social and political significance of their actions and their contribution to brazilian culture make the poet can, with simple beauty and art, join social denunciation lyricism. In his poetry are present the joys, the hopes, the struggles of the people, ideas, words that rise with the dignity of those who cry out for Justice, against all forms of exploitation of human beings.
\end{abstract}

Keywords: Patativa do Assaré. Option for the Poor.

\title{
Introdução
}

Patativa do Assaré participou de importantes momentos da história política brasileira e também de vários movimentos, entre eles as Ligas Camponesas, o movimento de resistência à ditadura militar, a campanha pela Anistia e pelas Diretas Já. Na área cultural participou de todos os principais movimentos culturais de seu tempo. Simbolizou para a juventude a partir dos anos de 1970 uma voz da resistência e das lutas democráticas. No ano de 1956, escreveu seu primeiro livro de poesias Inspiração Nordestina; torna-se conhecido nacionalmente em 1964 com a gravação de $A$ Triste Partida por Luiz Gonzaga, o Rei do Baião, música que sempre irá cantar em praticamente todos os seus shows e a única que fazia questão de falar a autoria da mesma, e da inveja que sentia por não tê-la composto. Cante lá que eu canto cá, de 1978, seu grande sucesso de vendas; Ispinho e Fulô, de 1988; Balceiro - Patativa e outros Poetas de Assaré, de 1991; Aqui tem coisa, de 1994; Balceiro 2 Patativa e outros Poetas de Assaré, de 2000; Cordel, de 2000; e o maravilhoso 
documentário sobre sua vida e obra - Patativa do Assaré - Ave Poesia, de Rosemberg Cariry, que foi lançado em 2007.

Sua vida e a obra apresentadas na relevância dos seus poemas, o significado religioso, social e político dos seus atos e a sua imensa contribuição à cultura brasileira fazem com que o poeta consiga, com singela beleza e arte, unir a denúncia social ao lirismo. Quem escuta ou lê sua poesia começa a pensar, emociona-se e conscientiza-se de tudo que está acontecendo no mundo, pois na sua poesia estão presentes as alegrias e as esperanças, todas as lutas do povo; estão reunidas ideias e palavras que se erguem com a dignidade guerreira dos que clamam por justiça, contra todas as formas de obscurantismo e de exploração do ser humano.

O Papa Francisco nos diz que no coração de Deus ocupam lugar privilegiado os pobres, tanto que o próprio Jesus se fez pobre. Para a Igreja, como nos diz a Evangelii Gaudium: Deus manifesta a sua misericórdia antes de mais nada a eles. Esta preferência divina tem consequências na vida de fé de todos os cristãos e cristãs, que são convocados a possuir os mesmos sentimentos que estão em Jesus de Nazaré. Inspirada por tal preferência, a Igreja fez uma Opção pelos Pobres, entendida como uma forma especial de primado na e da prática da caridade, da fraternidade, da amizade, da solidariedade cristã. A Opção pelos Pobres é um dos traços característicos do rosto da Igreja e do modo de ser cristão na América Latina e Caribe. Para restabelecer a justiça, é necessário que a situação do pobre seja levada em consideração em forma de prioridade.

Patativa do Assaré deixou uma obra poética riquíssima e um exemplo de vida marcado por uma voz que sempre apontou as mazelas e injustiças sofridas primeiro pelo povo do Nordeste, depois, apropriadas para o resto do país. Ele versejou sobre literatura e teologia quando falou, fala, sobre a fome e a sede, sobre seca e enchente, sobre dor e amor, sobre ingenuidade e ganância, sobre cangaceiros e beatos, sobre o diabo e Deus. Pesquisar o poeta é entrar em contato com uma força, uma criatividade, uma resistência que germina do mundo dos mais simples, que tem principalmente na teologia da libertação um lugar concreto: os pobres, os mais simples. 


\section{Poesia e Teologia: dois mundos que se encontram em Patativa do Assaré}

Antonio Manzatto ${ }^{1}$ nos diz que a teologia enquanto ciência tem suas fontes, seus métodos, seus sábios, seus princípios, tendo como base central a Revelação, Palavra de Deus que é a alma, o cerne de toda a teologia. Sendo assim, a teologia é uma ciência e a literatura é uma arte. Elas estabelecem relações recíprocas. A literatura tornou-se uma verdadeira profissão. Uma obra de arte, seja ela um livro ou uma pintura, recebe um reconhecimento internacional muito maior do que qualquer livro de teologia. A literatura adquiriu importância para o mundo contemporâneo. Sendo a literatura influenciada pelo seu meio, ela exerce também uma influência sobre a sociedade com a qual ela dialoga e se dirige. Ela tem suas próprias leis, seus temas, sua maneira de existir independente da teologia. Porém, ambas se tocam em vários sentidos e em vários pontos, sendo o nível cultural um exemplo.

Maria Clara Bingemer ${ }^{2}$ afirma que há uma afinidade constitutiva e uma irmandade ancestral entre teologia e literatura. Graças à espiritualidade, ambas decorrem da inspiração do teólogo e do artista. Elas se atraem e fazem o ser humano mais humano e a vida profundamente bela e digna. Portanto, literatura é uma arte verbal onde seu meio de expressão é a palavra; a poesia é a mais gratuita das práxis, é a inspiração, o entusiasmo criador; espiritualidade é aquilo que faz dentro do ser humano uma transformação e a teologia é uma linguagem segunda, posterior à revelação e a fé.

Patativa do Assaré, apelido de Antônio Gonçalves da Silva, era um agricultor pobre, nasceu em 5 de março de 1909 e faleceu em 8 de julho de 2002 na cidade de Assaré, Ceará. Viveu enquanto trabalhou como agricultor na Serra de Santana, situada a $18 \mathrm{~km}$ de Assaré. Ficou de 4 a 6 meses na escola quando criança, depois a abandonou, tornou-se autodidata. Desde cedo ao ouvir os cantadores e repentistas, parentes e amigos declamando as histórias narradas em folhetos de cordel, sentiu-se encantado pelo mundo da poesia. Por causa da seca que matava a população cearense e de grande parte do Nordeste, dos desmandos da política local, Patativa, desde menino, ouvindo aos mais velhos, e lendo de tudo o que encontrava ia construindo uma consciência a

\footnotetext{
${ }^{1}$ MANZATTO, Antonio. Teologia e Literatura - reflexão teológica a partir da antropologia contida nos romances de Jorge Amado. São Paulo: Edições Loyola, 1994.

${ }^{2}$ BINGEMER, Maria Clara. "Teologia e Literatura (afinidades e segredos compartilhados)". Revista Vida Pastoral 296 (2014), pp. 3-8.
} 
favor do povo da sua terra, a favor da defesa da vida de sua gente. Patativa era coerente. Pequeno proprietário de terras, filho de um pequeno proprietário de terras, sempre esteve ao lado dos pobres, dos oprimidos e sabia muito bem da importância de uma Reforma Agrária, daí o fato de ter se deixado fotografar enrolado na bandeira do MST (Movimento dos Trabalhadores Rurais sem Terra). Nunca se deixou deslumbrar pelo assédio de políticos ou empresários. Nunca achou que fez "sucesso". Nunca quis sair de sua Assaré. A opção de Patativa era pela ética, pela justiça social, em defesa dos excluídos. Ele foi porta-voz e intérprete dos desamparados de todo o Brasil. Patativa do Assaré ${ }^{3}$ é uma voz profética e poética do Brasil profundo.

\author{
Neste globo terrestre \\ apresento os versos meus \\ porém eu só tive um mestre \\ e esse mestre é Deus.
}

Patativa do Assaré era um religioso a seu modo. Não gostava de falar de suas devoções, dizia ser um território íntimo e que só interessava a ele. Sua religiosidade profunda se transmite em seus poemas. Sempre lutou pela ideia de fraternidade, igualdade, liberdade, justiça e misericórdia, princípios caros ao cristianismo primitivo e que o Papa Francisco não se cansa de pedir nos dias atuais. Patativa do Assaré rejeitava um pouco a exteriorização piedosa desse sentimento do sagrado. A marca profética de sua poesia é um serviço aos mais empobrecidos, estes a quem sempre devotou palavras de imensa esperança.

Segundo Luiz Tadeu Feitosa ${ }^{4}$, o poeta fazia um jogo de esconde-esconde de fatos de sua vida e de sua trajetória poética e artística constituindo um quase enigma, notando-se, porém, um ato litúrgico em suas ações, onde ele encontra conforto nos limites dos ritos: repetições e o improviso agendado e cuidadoso coerente com o rito maior, que é ele se mostrar mostrando sua obra a partir dos paradigmas da moral cristã onde se sobrepõem os valores da verdade e da justiça.

Cristiane Moreira Cobra, ${ }^{5}$ afirma que analisar a obra de Patativa do Assaré

\footnotetext{
${ }^{3}$ FEITOSA, Tadeu. Patativa do Assaré - Digo e não peço segredo. São Paulo: Escrituras, 2003. ${ }^{4}$ FEITOSA, Luiz Tadeu. Patativa do Assaré - A trajetória de um canto. São Paulo: Escrituras, 2003.

${ }^{5}$ COBRA, Cristiane Moreira. Patativa do Assaré - Uma hermenêutica criativa: a reinvenção da religiosidade na nação semiárida. São Paulo: Dissertação, 2006.
} 
exige relacionar três elementos: cultura popular, religiosidade e significado, considerando a poesia como manifestação representativa da cultura de um grupo, de um povo, de sua crença e recheada de significados.

Patativa ${ }^{6}$ irá trabalhar muitos de seus poemas com base na religiosidade popular, com todas as divergências carregadas de sentidos e significados singulares ao povo do sertão nordestino, muitas delas oriundas daquelas imagens propostas pela Igreja Católica Apostólica Romana como devoção constituída e legal:

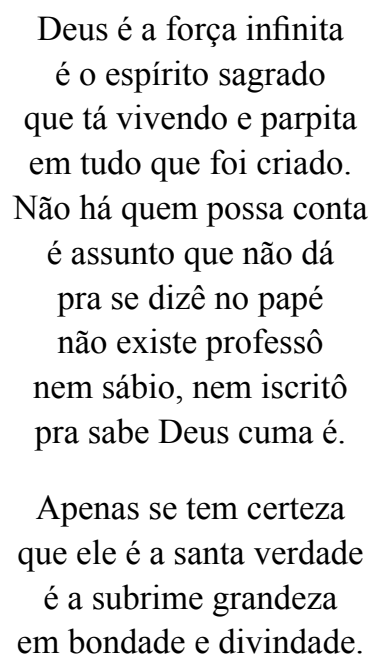

Antonio Iraildo Alves de Brito $^{7}$ relata que palavras como: divina providência, divino mestre, onipotente, nosso Senhor, autor profundo e outras do gênero são notáveis, e dentro de toda a obra do poeta, apresenta a visão de mundo que enfatiza o lugar de Deus e seu poder em relação às pessoas, à história e à natureza. $\mathrm{O}$ ato de compor era para Patativa do Assaré um dom de Deus! Para Patativa Deus é algo impronunciável, indizível, o que o colocaria dentro do respeito e temor característico do povo judeu de que mesmo nos dias atuais não pronunciam o tetragrama sagrado YHWH. Deus para o poeta escapa de qualquer tentativa de conceituação racional.

Patativa ao mesmo tempo que exercia o ofício de agricultor, exercia o de poeta. Na sua pequena propriedade em que cultivou vários elementos fez

\footnotetext{
${ }^{6}$ ASSARÉ, Patativa do. Ispinho e Fulô. São Paulo: Hedra, 2005.

${ }^{7}$ BRITO, Antonio Iraildo Alves de. Patativa do Assaré porta-voz de um povo - as marcas do sagrado em sua obra. São Paulo: Paulus, 2010.
} 
germinar sua poesia vital. Fez jorrar a água da vida numa terra marcada pela aridez e pela seca. Não desanimou. A natureza irá se apresentar como a porta de acesso às coisas divinas, a natureza será a sua escola. Sua poesia procede de uma fonte sagrada, sem a qual não existiria.

O eu poético de Patativa do Assaré se torna também o eu profético, portanto mediador de uma palavra de esperança, palavra de fé e de vida, palavra livre, palavra popular.

Um poeta, um profeta do povo, que anuncia, denuncia e ameaça.

\section{Patativa do Assaré e a Teologia da Libertação e do Povo.}

O primeiro livro de Patativa do Assaré foi Inspiração Nordestina, do ano de 1956, o poeta tinha por volta de 47, 48 anos de idade. Esta obra foi feita no período de maior criação do poeta entre os anos de 1930 a 1955, onde o poeta bulia a terra para o cultivo das sementes que fortaleceriam o corpo franzino, ao mesmo tempo que em sua mente e no seu coração brotariam as primeiras sementes poéticas, que marcariam sua vida dali por diante, no Ceará, depois em todo o Brasil e no exterior.

Entender o contexto de sua primeira criação é importante para a ponte que se construirá entre sua poesia-profecia com a Teologia da Libertação e com a Teologia do Povo. Inspiração Nordestina é anterior ao Concílio Ecumênico Vaticano II (1962-1965), ao Pacto das Catacumbas da Igreja Servidora e Pobre (16/11/1965) e à Conferência de Medellín (Colômbia, 1968); analisando-se os poemas, constata-se que os mesmos não levam em conta a religião enquanto instituição ou como credo estabelecido, apesar de verificar-se nuances fortes, uma mentalidade judaico-cristã com acentos do cristianismo católico, o objetivo é considerar a religião como uma janela aberta para conceber o mundo. Neste livro, o pensamento patativano a respeito de Deus, da religião e da fé é um pensamento em sua forma espontânea: fé popular. Não faz teologia sistemática, mas faz teologia como modo livre de falar de Deus. Os poemas falam de uma força sobrenatural inominável que moveria o mundo, mas também falam do diabo que levaria à ruína do mundo. A dicotomia entre o bem e o mal a partir de então nas obras do poeta sempre estará presente.

Estão presentes na obra a preocupação com os mais necessitados, com os famintos, com lascados, com os esquecidos pelo poder público, os marginalizados pela sociedade; o sentimento de fazer a justiça acontecer é gritante. 
Brito $^{8}$ irá dizer a respeito:

Inspiração Nordestina pode ser caracterizada pela defesa dos valores locais em tensão com outros valores externos. A tensão se dá, sobretudo, quando esses valores de fora chegam para escravizar o sertanejo. Tanto o escravizar materialmente, pela exploração do trabalho, quanto pela "invasão da mente", isto é, pelas interferências de ideias contrárias à tradição local. Dizer a verdade, nesse sentido, é mostrar um sertão que, embora sofrido, é belo. Pode até ser pobre, mas tem em si a potência de assegurar aos seus a garantia da felicidade. Dizer a verdade ainda é fazer da voz um grito de denúncia a um modelo de política que prefere fechar os olhos às potencialidades do sertão e à força e resistência do sertanejo. Por isso, se diz que seu livro é a "verdade gravada nas folhas", é o registro de um canto que se entoa em nome da aldeia e daí encontra brechas para o mundo.

A poesia de Patativa do Assaré é anterior a todo o processo de educação na fé que culminará no Vaticano II, na escrituração dos 13 princípios do Pacto das Catacumbas e na Opção pelos Pobres assumida na Conferência de Medellín e passa adiante, mesmo depois de sua morte; sua consciência religiosa tem matriz popular com enfoque libertador. Ele observa o que acontece ao seu redor, com sua gente, com a natureza e começa a partir dos versos que vai criando, vai abrindo os olhos dos amigos, dos vizinhos, da população de Assaré para o que estava acontecendo ali, ele já assumia na sua poesia as virtudes e tarefas mesmo sem ter a nomenclatura de Teologia da Libertação e Teologia do Povo.

Leonardo Boff ${ }^{9}$ explica as diferenças entre a Teologia do Povo, do Papa Francisco, e a Teologia da Libertação:

As diferenças são de método, e não de conteúdo e de objetivos. Ambas se propõem à libertação. A Teologia do Povo parte do povo oprimido ou da cultura silenciada e busca a libertação através da potenciação dos valores

\footnotetext{
${ }^{8}$ Idem.

${ }^{9}$ BOFF, Leonardo. "O amor e a misericórdia são categorias centrais da teologia e prática de Francisco". Revista do Instituto Humanitas Unisinos, São Leopoldo, 19 de maio de 2015. Disponível em: <http://www.ihuonline.unisinos.br/index.php?option=com_content\&view=art icle\&id $=5924 \&$ secao $=465>$. Acesso em 19 de maio de 2015 .
} 
vividos pelo povo, com seu ethos próprio, suas festas e tradições. A Teologia da Libertação, como veio formulada, primeiramente, por Gustavo Gutiérrez, se preocupava, antes de tudo, na identificação das causas que levaram o povo a ser oprimido. Para isso se utilizaram de forma meramente instrumental, sem incorporar a ideologia subjacente, das categorias da tradição crítica, elaborada principalmente por Marx. Este mostrava que o pobre, na verdade, é feito pobre, é um empobrecido como consequência da exploração que a classe capitalista faz sobre a classe operária.

A versão argentina evita a questão de classe, parte do povo oprimido como um dado imediato, sem precisar identificar as causas que o levaram a esta situação. Talvez tenha evitado o recurso da tradição crítica para evitar a desconfiança e perseguição dos militares que se opunham a qualquer sinal que denotasse presença de categorias marxistas. Mas essa é uma interpretação minha. Cabe enfatizar que estas teologias não se opõem, mas se compõem. E, também, nem uma quer ser alternativa à outra, pois ambas assumem os mesmos objetivos.

Ambas as teologias estão aí para ajudar o povo latino-americano e caribenho a se aproximar do amor de Deus, do mesmo jeito o faz Patativa do Assaré, ao fazer da sua poesia uma união entre fé e política, tomando partido em favor do mais simples, em favor da defesa da vida: humana, dos animais, da natureza em geral.

\section{Conclusão}

O cotidiano é um grande tesouro, adentrar este cotidiano todos os dias e em todos os seres humanos é o que a arte se permite fazer. Ela revela o transcendente na vida. Assim acontece com a poesia e com a teologia, ambas em ambiente próprio ou em perfeita harmonia revelam o transcendente.

Certa vez o teólogo Gustavo Gutiérrez ${ }^{10}$ disse: "a melhor forma de falar de Deus é por meio da poesia"; Patativa do Assaré realizou isso durante toda a sua vida, se tornou por causa da palavra um agente do sagrado, imerso nas alegrias e esperanças de sua gente, atento aos sofrimentos e angústias do seu povo, não abriu mão do sagrado em sua obra, se tornou um poeta-profeta na linha de Jesus de Nazaré, pois trazia em seu coração uma compaixão que o levava amar ainda mais os seus semelhantes.

\footnotetext{
${ }^{10}$ BRITO, Antonio Iraildo Alves de. "Patativa do Assaré: uma voz poética e profética do Brasil profundo”. Revista Vida Pastoral 296 (2014), pp. 23-32.
} 
Como nos diz José Antonio Pagola ${ }^{11}$ :

Jesus não explicou diretamente sua experiência do reino de Deus. Ao que parece, não the era fácil comunicar por meio de conceitos o que ele vivia em seu íntimo. Não utilizou a linguagem dos escribas para dialogar com os camponeses da Galileia. Também não sabia falar com o estilo solene dos sacerdotes de Jerusalém. Recorreu à linguagem dos poetas. Com criatividade inesgotável, inventava imagens, concebia belas metáforas, sugeria comparações e, sobretudo, narrava com maestria parábolas que cativavam as pessoas. A linguagem de Jesus é inconfundível. Não há em suas palavras nada de artificial ou forçado; tudo é claro e simples. Ele não precisa recorrer a ideias abstratas ou frases complicadas; comunica o que vive. Sua palavra se transfigura ao falar de Deus àquelas pessoas do campo.

O profetismo em Patativa está como aquele que interpreta os fatos do dia a dia e a realidade social e política do ponto de vista de Deus. Isso continua sendo assim hoje em dia. Embora ninguém tenha nenhum sinal especial, nem tenha recebido nenhum sinal milagroso, toda pessoa que busca a intimidade de Deus é chamado a descobrir o que ele nos diz através da realidade da vida nossa e do mundo. E aí temos que viver aquilo e temos também de testemunhálo aos outros.

O profeta não é uma espécie de torneira que a gente abre e sempre sai água, ou seja, um oráculo ou palavra divina. Não é assim uma coisa mágica nem excepcional.

O profeta é uma pessoa comum, que vive a vida nas buscas e nas incertezas, como todas as pessoas humanas.

O que o profeta tem de diferente é essa mania de buscar sempre o que Deus quer nos dizer através dos acontecimentos e também essa teimosia de transmitir aos outros, pela sua forma de viver e pela sua palavra o que the parece o que Deus está querendo dizer.

Jesus de Nazaré, ele mesmo, ao lidar com as pessoas, irradiava para elas o que aprendeu ao longo dos anos da sua vida no contato com Deus, com os pais, com o povo.

O que significa ter fome e sede de justiça?

Para o profeta Isaías, buscar a justiça e buscar a Deus eram como os dois lados da mesma medalha, ou seja, quem busca a justiça está em busca de

${ }^{11}$ PAGOLA, José Antonio. Jesus aproximação histórica. 5.ed. Petrópolis: Vozes, 2012. 
Deus. Jesus afirma a mesma coisa quando diz: "Buscai primeiro o Reino de Deus e a sua justiça".

Buscar o Reino de Deus se faz buscando a justiça. A fome e a sede de Deus e de justiça percorre a Bíblia de ponta a ponta. Ser justo significa estar no lugar onde Deus nos quer. O caminho que nos leva até esse lugar é nos indicado pela Lei de Deus.

Mas a misericórdia de Deus tem a primazia sobre a lei.

Para Jesus, nossa justiça diante de Deus não é fruto de nossas observâncias, mas é um dom que recebemos de Deus.

Temos que observar a lei de Deus, sim, sempre, mas não para merecer ou comprar o céu. Observamos a lei, até mais que os próprios fariseus, mas para retribuir a imensa bondade de Deus conosco.

Para poder ser justo e chegar até o lugar onde Deus me quer não basta olhar só minha vida pessoal, pois vivo numa sociedade, faço parte de um povo, sou membro de uma comunidade. Não é possível amar a Deus sem olhar o próximo, sem me preocupar com o próximo, sem me envolver com o próximo.

Observância e Gratuidade são os dois lados da mesma medalha: esforço nosso e dom de Deus; previdência humana e providência divina; política e fé; luta e festa; planejar e sonhar. Um lado só, sem o outro, tornaria incompleto nosso relacionamento com Deus.

Observância sem gratuidade leva a um legalismo exagerado que destrói a vida e mata a alegria.

Gratuidade sem observância leva a um ritualismo vazio e mágico sem compromisso.

Jesus uniu os dois lados.

Patativa do Assaré soube observar tudo isso.

\section{Referências bibliográficas}

ASSARÉ, Patativa do. Ispinho e Fulô. São Paulo: Hedra, 2005.

BINGEMER, Maria Clara. "Teologia e Literatura (afinidades e segredos compartilhados)". Revista Vida Pastoral 296 (2014), pp. 3-8.

BOFF, Leonardo. "O amor e a misericórdia são categorias centrais da teologia e prática de Francisco". Revista do Instituto Humanitas Unisinos, São Leopoldo, 19 de maio de 2015. Disponível em: <http://www.ihuonline. 
unisinos.br/index.php?option $=$ com_content\&view=article\&id $=5924 \&$ s ecao $=465>$. Acesso em 19 de maio de 2015.

BRITO, Antonio Iraildo Alves de. Patativa do Assaré: porta-voz de um povo - as marcas do sagrado em sua obra. São Paulo: Paulus, 2010.

BRITO, Antonio Iraildo Alves de. "Patativa do Assaré: uma voz poética e profética do Brasil profundo". Revista Vida Pastoral 296 (2014), pp. 23-32.

COBRA, Cristiane Moreira. Patativa do Assaré - Uma hermenêutica criativa: a reinvenção da religiosidade na nação semiárida. São Paulo: Dissertação, 2006.

FEITOSA, Luiz Tadeu. Patativa do Assaré - A trajetória de um canto. São Paulo: Escrituras, 2003.

FEITOSA, Tadeu. Patativa do Assaré - Digo e não peço segredo. São Paulo: Escrituras, 2003.

MANZATTO, Antonio. Teologia e Literatura - reflexão teológica a partir da antropologia contida nos romances de Jorge Amado. São Paulo: Edições Loyola, 1994.

PAGOLA, José Antonio. Jesus aproximação histórica. 5.ed. Petrópolis: Vozes, 2012.

Emerson Sbardelotti Tavares Mestre em Teologia Sistemática pela Pontifícia Universidade

Católica de São Paulo Bolsista CAPES

São Paulo / SP - Brasil E-mail: sbardelotti@gmail.com

Recebido em: 21/05/15

Aprovado em: 30/07/15 